\title{
Association between Growth Differentiation Factor 15 and Non-Dipping Circadian Pattern in Patients with Newly Diagnosed Essential Hypertension
}

\author{
Erdoğan Sökmen ${ }^{a} \quad$ Cahit Uçar ${ }^{b}$ Serkan Sivri ${ }^{a}$ Mustafa Çelik ${ }^{a}$ \\ Yalçın Boduroğlua Murat Erer $^{a} \quad$ Alp Yıldırıma ${ }^{a}$ Bilal İlanbey ${ }^{c}$ \\ ${ }^{a}$ Department of Cardiology, Ahi Evran University Training and Research Hospital, Kirsehir, Turkey; ${ }^{b}$ Department \\ of Internal Medicine, Ahi Evran University Training and Research Hospital, Kirsehir, Turkey; ${ }^{\mathrm{C}}$ Department of \\ Biochemistry, Ahi Evran University Training and Research Hospital, Kirsehir, Turkey
}

\section{Significance of the Study}

- Data suggests that growth differentiation factor 15 (GDF-15) has a potential association with the shortand long-term prognosis in cardiovascular diseases. There is no study evaluating the relationship of GDF-15 with the circadian pattern of hypertension (HT). Hereby, we investigated whether there is a diagnostic association between dipping and non-dipping blood pressure pattern in HT patients and found such an independent association.

\section{Keywords}

GDF-15 · Non-dipper hypertension · Circadian pattern ·

Dipping hypertension

\begin{abstract}
Objective: Non-dipper hypertension (HT) confers greater risk compared with dipper HT. Growth differentiation factor 15 (GDF-15) recently emerged as a novel and independent marker of cardiovascular disease, both in diagnostic and prognostic scopes. Our aim was to evaluate the relationship of circadian blood pressure (BP) pattern with serum GDF-15 level in newly diagnosed HT patients without left ventricular hypertrophy. Subjects and Methods: Newly diagnosed nondipper $(n=66)$ and dipper $(n=60)$ HT patients were selected according to 24-h ambulatory BP monitoring (ABPM). The controls comprised healthy normotensive subjects $(n=31)$.
\end{abstract}

Data was collected through physical examination, laboratory analysis, ABPM, and echocardiography. GDF-15 was measured using ELISA. Results: Greater GDF-15 level was found in the non-dippers compared with the dippers and the controls $(557.53 \pm 91.7,513.79 \pm 62.86$, and $494.44 \pm 79.30 \mathrm{ng} / \mathrm{L}$, respectively, $p<0.001)$. In bivariate linear correlation analysis, GDF-15 correlated positively with glomerular filtration rate $(r=0.180, p=0.030)$, total cholesterol $(r=0.170, p=$ $0.038)$, septal $E / E^{\prime}$ ratio $(r=0.344, p=0.001)$, lateral $E / E^{\prime}$ ratio $(r=0.366, p<0.001)$, nighttime systolic BP $(r=0.166, p=$ $0.046)$, and nighttime diastolic BP ( $r=0.188, p=0.024)$; however, it correlated negatively with septal and lateral $E^{\prime}$ velocities ( $r=0.268, p=0.005$ and $r=0.236, p=0.013$, respectively). Furthermore, GDF-15 level and nighttime diastolic BP remained independently associated with non-dipper HT. In ROC analysis, optimal cutoff value for GDF-15 was $524.6 \mathrm{ng} / \mathrm{L}$ with $56.7 \%$ sensitivity and $72.4 \%$ specificity (AUC: $0.676,95 \%$

\begin{tabular}{ll}
\hline KARGER & $\begin{array}{l}\text { (c) } 2019 \text { The Author(s) } \\
\text { Published by S. Karger AG, Basel }\end{array}$ \\
E-Mail karger@karger.com & $\begin{array}{l}\text { This is an Open Access article licensed under the Creative Commons } \\
\text { Attribution-NonCommercial-4.0 International License (CC BY-NC) } \\
\text { (http://www.karger.com/Services/OpenAccessLicense), applicable to } \\
\text { the online version of the article only. Usage and distribution for com- } \\
\text { mercial purposes requires written permission. }\end{array}$
\end{tabular}

Erdoğan Sökmen

Department of Cardiology, Ahi Evran University Training and Research Hospital Kervansaray Mah. 2019, Sok. No. 1

TR-40100 Kirsehir (Turkey)

E-Mail erdoganmen@gmail.com 
Cl: $0.580-0.772, p<0.05)$. Conclusion: Our results showed GDF-15 upregulation in the non-dipper HT group. GDF-15 and nighttime diastolic BP were independently associated with the non-dipping pattern. This study may suggest possible utilization of GDF-15 in the prediction of non-dipper HT.

(C) 2019 The Author(s)

Published by S. Karger AG, Basel

\section{Introduction}

Essential hypertension (EH) has been an explicit reason for cardiovascular (CV) morbidity and mortality throughout the world. The diagnosis of hypertension (HT) most of the time relies upon repeated office blood pressure (BP) measurements; however, a 24-h ambulatory $\mathrm{BP}$ monitoring $(\mathrm{ABPM})$ yields much further data regarding the status of $\mathrm{EH}$ including the circadian variations in BP. Normally, a $\geq 10 \%$ fall in nocturnal BP is expected compared with daytime $\mathrm{BP}$, which is termed as a "dipping BP" pattern. On the other hand, a non-dipping pattern is characterized by a $<10 \%$ decline in $\mathrm{BP}$ during nighttime [1]. Furthermore, the presence of a non-dipping BP pattern confers far greater $\mathrm{CV}$ risk and hence predicts worse long-term prognosis in $\mathrm{EH}$ patients compared with the dipping BP pattern in HT patients [2].

Growth differentiation factor 15 (GDF-15) belongs to the transforming growth factor- $\beta$ cytokine superfamily [3]. Normally, it is secreted from a congeries of cells such as endothelial cells, vascular smooth muscle cells, and macrophages in a trace amount. However, diverse pathological conditions conducive to stress response may boost its secretion from both the cardiac and non-cardiac tissues [4]. Previous studies reported elevated levels of GDF15 in several disease conditions including acute coronary syndrome, stable coronary arterial disease, diabetes mellitus, solid cancers, EH, atrial fibrillation, and acute and chronic heart failure [4-9]. In many of these disease conditions, GDF-15 has proved to be a predictor of prognosis more than a marker of diagnosis [4]. Accordingly, GDF15 was also suggested as an independent predictor for allcause mortality in the general population [10]. Two previous studies showed that GDF-15 levels in EH patients with left ventricular hypertrophy $(\mathrm{LVH})$ were greater compared with those of $\mathrm{EH}$ patients without $\mathrm{LVH}$ and healthy controls $[11,12]$.

Although the predictive role of GDF-15 is well recognized in $\mathrm{EH}$ patients with $\mathrm{LVH}$, its relationship with the circadian BP pattern in newly diagnosed EH pa- tients has yet to be elucidated. Hereby, we intended to evaluate the relationship of serum GDF-15 level with the circadian BP pattern in newly diagnosed EH patients without LVH.

\section{Subjects and Methods}

\section{Patient Population and Design}

Our prospective and single-center study consecutively enrolled a total of 126 patients diagnosed with a new HT between May 2018 and October 2018. Moreover, 31 age- and sex-matched healthy subjects were recruited for a control group. The patients had not been prescribed any anti-hypertensive medication formerly. A comprehensive physical examination and a detailed inquiry about the patients' past medical history were performed. The enrolled patients were further subdivided into dipper $(n=60$ patients) and non-dipper ( $n=66$ patients) groups on the basis of ABPM readings. BMI was calculated by dividing the weight in kilograms with the square of height in meters. We set the exclusion criteria as follows: diabetes mellitus, severe kidney failure, atherosclerotic CV disease, secondary HT, endocrine disorders, atrial fibrillation, acute infections, chronic inflammatory illnesses, left ventricular (LV) systolic dysfunction, cerebrovascular diseases, chronic obstructive pulmonary disease, smoking, alcohol or substance addiction, and being on anti-inflammatory or steroid drugs.

\section{Twenty-Four-Hour Ambulatory BP Measurement}

All the study patients with $\mathrm{BP} \geq 140 / 90 \mathrm{~mm} \mathrm{Hg}$ underwent ABPM (Bravo HR ABP SunTech Medical Inc., Morrisville, NC, USA). Measurement of BP was performed at 15-min intervals during daytime (6:00 a.m.-10:00 p.m.) and 30-min intervals during nighttime (10:00 p.m.-06:00 a.m.). Overall, the BP recordings were analyzed to obtain 24-h mean systolic BP, 24-h mean diastolic BP, daytime mean systolic BP, daytime mean diastolic BP, nighttime mean systolic BP, and nighttime mean diastolic BP in every patient. The diagnosis of HT was given to any patient with 24-h mean systolic pressure $>130 \mathrm{~mm} \mathrm{Hg}$ and/or diastolic pressure $>80 \mathrm{~mm} \mathrm{Hg}$, daytime mean systolic pressure $>135 \mathrm{~mm} \mathrm{Hg}$ and/or diastolic pressure $>85 \mathrm{~mm} \mathrm{Hg}$, or nighttime systolic pressure $>120$ $\mathrm{mm} \mathrm{Hg}$ and/or diastolic pressure $>70 \mathrm{~mm} \mathrm{Hg}$ [13]. Dipping and non-dipping patterns were defined as $\geq 10$ and $<10 \%$ BP decline during nighttime, respectively.

\section{Echocardiography}

All the study participants were examined comprehensively using a Vivid Echocardiography device (GE Vingmed Ultrasound AS, Horten, Norway). Left ventricular ejection fraction (LVEF) was determined by use of the modified Simpson's rule. Early (E) and late (A) transmitral inflow velocities, E-deceleration time (EDT), and early $\left(\mathrm{E}^{\prime}\right)$ and late $\left(\mathrm{A}^{\prime}\right)$ diastolic mitral annular velocities were measured as per the relevant guideline [14]. LV mass index (LVMI) was determined by use of the Devereux formula $[15,16]$. LVH was defined as LVMI $>95 \mathrm{~g} / \mathrm{m}^{2}$ for females and $>$ $115 \mathrm{~g} / \mathrm{m}^{2}$ for males according to the relevant literature [16]. EH patients complying with the term "LVH" were not included in the study. 
Table 1. Baseline demographic and clinical characteristics of the study population

\begin{tabular}{|c|c|c|c|c|}
\hline Characteristics & $\begin{array}{l}\text { Non-dipper HT } \\
(n=66)\end{array}$ & $\begin{array}{l}\text { Dipper HT } \\
(n=60)\end{array}$ & $\begin{array}{l}\text { Controls } \\
(n=31)\end{array}$ & $p$ total \\
\hline Female gender & $34(51.5)$ & $25(41.7)$ & $11(35.5)$ & 0.282 \\
\hline Age, years & $46.4 \pm 7.8$ & $47.6 \pm 4.7$ & $49.74 \pm 5.4$ & 0.055 \\
\hline $\mathrm{BMI}, \mathrm{kg} / \mathrm{m}^{2}$ & $27.1 \pm 1.7$ & $26.71 \pm 1.4$ & $26.58 \pm 1.6$ & 0.215 \\
\hline GDF-15, ng/L & $557.53 \pm 91.7^{*}$ & $513.79 \pm 62.86^{* *}$ & $494.44 \pm 79.30$ & $<0.001^{* * *}$ \\
\hline Glucose, mg/dL & $89.87 \pm 4.1$ & $89.68 \pm 5.3$ & $89.9 \pm 7.1$ & 0.974 \\
\hline $\mathrm{GFR}, \mathrm{mL} / \mathrm{min} / 1.73 \mathrm{~m}^{2}$ & $96.3 \pm 14.7$ & $97.6 \pm 14.1$ & $95.2 \pm 15.8$ & 0.757 \\
\hline $\mathrm{ALT}, \mathrm{U} / \mathrm{L}$ & $21.79 \pm 13.29$ & $25.28 \pm 12.14$ & $22.74 \pm 8.77$ & 0.275 \\
\hline Triglyceride, mg/dL & $162.78 \pm 73.15$ & $176.88 \pm 77.14$ & $173.48 \pm 65.75$ & 0.541 \\
\hline Total cholesterol, mg/dL & $183.69 \pm 37.49$ & $188.90 \pm 31.13$ & $191.29 \pm 31.74$ & 0.525 \\
\hline $\mathrm{LDL}, \mathrm{mg} / \mathrm{dL}$ & $102.27 \pm 28.73$ & $108.01 \pm 26.96$ & $112.74 \pm 27.72$ & 0.200 \\
\hline $\mathrm{HDL}, \mathrm{mg} / \mathrm{dL}$ & $48.1 \pm 11.66$ & $44.38 \pm 10.07$ & $43.58 \pm 6.74$ & 0.064 \\
\hline $\mathrm{CRP}, \mathrm{mg} / \mathrm{dL}$ & $0.45 \pm 0.37$ & $0.38 \pm 0.33$ & $0.42 \pm 0.34$ & 0.491 \\
\hline $\mathrm{WBC}, \times 10^{9} / \mathrm{L}$ & $7.73 \pm 1.8$ & $8.60 \pm 2.01$ & $8.19 \pm 2.04$ & 0.096 \\
\hline $\mathrm{Hb}, \mathrm{g} / \mathrm{dL}$ & $15.1 \pm 1.7$ & $15.2 \pm 2.0$ & $14.9 \pm 1.9$ & 0.257 \\
\hline Plt, $\times 10^{9} / \mathrm{L}$ & $285.4 \pm 70.4$ & $294.1 \pm 69$ & $296.2 \pm 92$ & 0.761 \\
\hline \multicolumn{5}{|l|}{ 24- $h$ ABPM readings } \\
\hline 24-h SBP, mm Hg & $133.31 \pm 9.3$ & $134.41 \pm 12.3$ & - & 0.456 \\
\hline 24-h DBP, mm Hg & $86.09 \pm 7.1$ & $87.01 \pm 8.3$ & - & 0.463 \\
\hline Daytime SBP, mm Hg & $133.93 \pm 9.3$ & $139.30 \pm 13.2$ & - & $<0.001$ \\
\hline Daytime DBP, mm Hg & $85.87 \pm 7.8$ & $90.66 \pm 8.4$ & - & $<0.001$ \\
\hline Nighttime SBP, mm Hg & $131.09 \pm 11.2$ & $120.96 \pm 11.2$ & - & $<0.001$ \\
\hline Nighttime DBP, mm Hg & $83.8 \pm 8.9$ & $76.8 \pm 8.4$ & - & $<0.001$ \\
\hline \multicolumn{5}{|l|}{ Echocardiography } \\
\hline IVS, $\mathrm{mm}$ & $10.8(10.30 \sim 11.22)$ & $10.4(10.2 \sim 11)$ & $10.4(10.2 \sim 11)$ & 0.958 \\
\hline PWT, mm & $10(8.9 \sim 10.27)$ & $9.30(9 \sim 10)$ & $9.3(8.9 \sim 9.77)$ & 0.394 \\
\hline LVEDD, mm & $46.25(44 \sim 49.9)$ & $46(45.1 \sim 50)$ & $45.9(45.1 \sim 50)$ & 0.515 \\
\hline LVEF, \% & $63.5(61 \sim 65)$ & $63(62 \sim 65)$ & $62(65 \sim 65.25)$ & 0.567 \\
\hline Left atrium, mm & $37.3(34 \sim 40.6)$ & $33(32 \sim 36.7)$ & $32.5(32 \sim 36.05)$ & 0.195 \\
\hline E velocity, $\mathrm{cm} / \mathrm{s}$ & $65.6(60.9 \sim 76.7)$ & $69.8(46.4 \sim 83)$ & $68.8(57 \sim 81.5)$ & 0.382 \\
\hline A velocity, $\mathrm{cm} / \mathrm{s}$ & $84.25(69.3 \sim 93.4)^{\mathrm{a}}$ & $68.6(50.3 \sim 85.0)^{\mathrm{b}}$ & $51.35(48 \sim 67.5)^{c}$ & $<0.001$ \\
\hline $\mathrm{E} / \mathrm{A}$ & $0.83(0.7 \sim 1.05)^{\mathrm{a}}$ & $1.14(0.81 \sim 1.34)^{\mathrm{a}, \mathrm{b}}$ & $1.24(1.15 \sim 1.37)^{\mathrm{b}}$ & $<0.001$ \\
\hline $\mathrm{EDT}, \mathrm{ms}$ & $192(167 \sim 236)$ & $201(165 \sim 253)$ & $178(168.5 \sim 193)$ & 0.073 \\
\hline $\mathrm{E}^{\prime}$ septal, $\mathrm{cm} / \mathrm{s}$ & $8.85(8.5 \sim 9.1)^{\mathrm{a}}$ & $9.6(7.7 \sim 10.65)^{\mathrm{a}}$ & $10.3(9.9 \sim 11.52)^{b}$ & 0.031 \\
\hline $\mathrm{A}^{\prime}$ septal, $\mathrm{cm} / \mathrm{s}$ & $12.4(11.7 \sim 13.6)^{\mathrm{a}}$ & $12(10.3 \sim 13.45)^{\mathrm{a}}$ & $8.9(7.97 \sim 10.3)^{\mathrm{b}}$ & $<0.001$ \\
\hline $\mathrm{E}^{\prime}$ lateral, $\mathrm{cm} / \mathrm{s}$ & $10.7(8.4 \sim 12.5)$ & $9.7(9.2 \sim 13.6)$ & $10.25(9.35 \sim 13.12)$ & 0.674 \\
\hline $\mathrm{A}^{\prime}$ lateral, $\mathrm{cm} / \mathrm{s}$ & $12.85(11.5 \sim 14.6)^{\mathrm{a}}$ & $12.6(10.2 \sim 13.7)^{\mathrm{a}}$ & $9.7(8.75 \sim 10.2)^{b}$ & $<0.001$ \\
\hline E/E' septal & $7.41(6.92 \sim 8.38)$ & $6.79(4.9 \sim 9.83)$ & $6.55(5.84 \sim 7.08)$ & 0.051 \\
\hline $\mathrm{E} / \mathrm{E}^{\prime}$ lateral & $6.14(5.23 \sim 8.21)$ & $6.08(4.44 \sim 8.12)$ & $6.07(5.56 \sim 6.42)$ & 0.618 \\
\hline LVMI, $\mathrm{g} / \mathrm{m}^{2}$ & $86.5(75.4 \sim 102.6)$ & $86.7(76.8 \sim 103.3)$ & $85.1(73.4 \sim 102.2)$ & 0.392 \\
\hline
\end{tabular}

Values are $n(\%)$, mean \pm standard deviation, or median (25th and 75 th interquartile range). BMI, body-mass index; GDF-15, growth differentiation factor-15; GFR, glomerular filtration rate; ALT, alanine aminotransferase; LDL, low-density lipoprotein cholesterol; HDL, high-density lipoprotein cholesterol; CRP, C-reactive protein; WBC, white blood cell count; Hb, hemoglobin; Plt, platelet count; ABPM, ambulatory blood pressure monitoring; SBP, systolic blood pressure; DBP, diastolic blood pressure; IVS, interventricular septum thickness; PWT, posterior left ventricular wall thickness; LVEDD, left ventricular end-diastolic diameter; LVEF, left ventricular ejection fraction; EDT, transmitral E-deceleration time; LVMI, left ventricular mass index. There is no statistically significant difference between the pairs marked with the same letter within the same line $(p>0.05) .{ }^{\star} p<0.001$, for the pair-wise comparison between the non-dipper group and healthy controls; $p=0.007$, for the pair-wise comparison between the non-dipper group and the dipper group; ${ }^{* *} p=0.289$, for the pair-wise comparison between the dipper group and healthy controls; ${ }^{* * *} p$ (total) $<0.001$, for total comparison between all groups. 


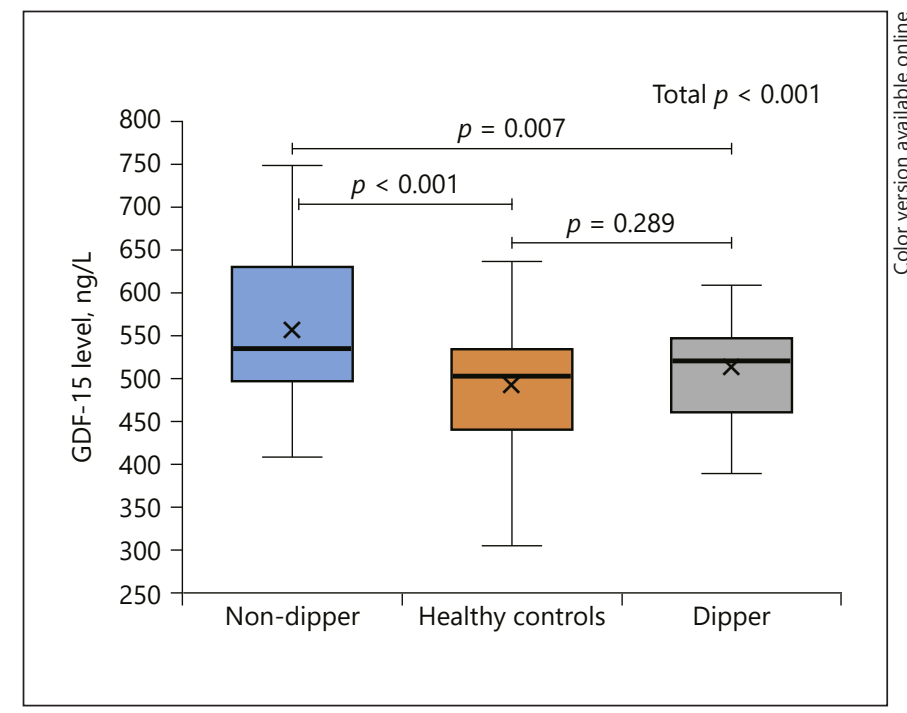

Fig. 1. Graphic representation of serum GDF-15 levels in the groups.

\section{Blood Tests and GDF-15 Measurement}

Blood samples were drawn through venipuncture into gel-containing serum tubes between 8:00 a.m. and 9:00 a.m. after at least 12 -h fasting and the serum was separated from the cells by centrifuging at $1,500 \mathrm{~g}$ for $10 \mathrm{~min}$. The serum was stored at $-80^{\circ} \mathrm{C}$ until the time of assay. Before analysis, the samples were thawed at room temperature. GDF-15 levels were measured using an enzymelinked immunosorbent assay (ELISA) via a commercially available assay (www.relassay.com, Gaziantep, Turkey) in accordance with the manufacturer's instructions. The limit of detection of the assay was $5.09 \mathrm{ng} / \mathrm{L}$. The intra- and interassay coefficients of variation for GDF-15 were $<10$ and $<12 \%$, respectively.

\section{Statistical Analysis}

SPSS (SPSS for Windows, Version 21.0; IBM Corp., Armonk, NY, USA) was used for the statistical analysis of the study parameters. Kolmogorov-Smirnov and Shapiro-Wilk tests were used for the normality of quantitative data. Continuous variables were expressed as mean \pm standard deviation and median (25th and 75th interquartile range), while categorical variables were expressed as numbers (percentages). The study variables were compared between the groups by using the $\chi^{2}$ test, one-way analysis of variance (ANOVA), and the Kruskal-Wallis $\mathrm{H}$ test, as per the type of variable. Comparison between groups in which a statistical difference was observed via ANOVA was performed using the Duncan multiple comparison test. Furthermore, pair-wise comparison between groups in which the Kruskal-Wallis $\mathrm{H}$ test revealed a statistically significant difference was performed using the Mann-Whitney $U$ test, and the findings were assessed after Bonferroni correction. The relationship between GDF-15 and the other variables in the study population was analyzed using bivariate linear correlation analysis. Multivariate logistic regression analysis was implemented in order to determine the predictors of non-dipper HT. Finally, receiver operating characteristic (ROC) curve analysis was performed to define a diagnostic cutoff value for non-dipper HT. $p<0.05$ was considered to be statistically significant.

GDF-15 and Circadian Pattern of Hypertension
Table 2. Bivariate linear correlation analysis according to serum GDF-15 levels in all patients

\begin{tabular}{lcr}
\hline & Coefficient & $p$ \\
\hline GFR & $0.180^{*}$ & 0.030 \\
Total cholesterol & $0.170^{*}$ & 0.038 \\
E' septal & $-0.268^{* *}$ & 0.005 \\
E' lateral $^{\prime}$ & $-0.236^{*}$ & 0.013 \\
E/E' septal & $0.344^{* *}$ & 0.001 \\
E/E' lateral & $0.366^{* *}$ & $<0.001$ \\
Nighttime SBP & $0.166^{*}$ & 0.046 \\
Nighttime DBP & $0.188^{*}$ & 0.024
\end{tabular}

GFR, glomerular filtration rate; SBP, systolic blood pressure; DBP, diastolic blood pressure. ${ }^{*}$ Significance level at $5 \%$; ${ }^{* *}$ significance level at $1 \%$.

\section{Results}

Demographic and clinical characteristics of the enrolled subjects are presented in Table 1 . The groups were similar regarding gender distribution, age, BMI, and baseline biochemical and hematological parameters. GDF-15 level was significantly greater in the non-dipper HT group, compared with the dippers and the controls $(557.53 \pm 91.7,513.79 \pm 62.86$, and $494.44 \pm 79.30 \mathrm{ng} / \mathrm{L}$, respectively, $p<0.001$ ) (Table 1; Fig. 1); however, in the pair-wise comparison between the dipper HT and control groups the difference was not significant regarding GDF15 levels $(\mathrm{p}>0.05)$.

Non-dipper and dipper HT groups did not show a significant difference regarding 24 -h mean systolic and diastolic BP. Furthermore, daytime mean systolic and diastolic BP were significantly greater in the dipper HT group, whereas nighttime mean systolic and diastolic BP were significantly greater in non-dippers $(p<0.001)$ (Table 1$)$.

LV wall thicknesses, LV end-diastolic diameter, LVEF, EDT, left atrium diameter, E velocity, lateral $\mathrm{E}^{\prime}$ velocity, septal $\mathrm{E} / \mathrm{E}^{\prime}$ ratio, lateral $\mathrm{E} / \mathrm{E}^{\prime}$ ratio, and $\mathrm{LVMI}$ were similar among the groups $(p>0.05)$. Additionally, the A velocity was greater and $\mathrm{E} / \mathrm{A}$ ratio was lower in the non-dippers, compared with the dippers and the controls $(p<0.001)$. Pair-wise comparison of the $2 \mathrm{HT}$ groups displayed no significant difference regarding septal $\mathrm{E}^{\prime}$, septal $\mathrm{A}^{\prime}$, and lateral $\mathrm{A}^{\prime}$ velocities, all of which, however, were significantly better in the control group (Table 1).

In bivariate linear correlation analysis, serum GDF-15 levels correlated positively with glomerular filtration rate $(r=0.180, p=0.030)$, total cholesterol $(r=0.170, p=$ 


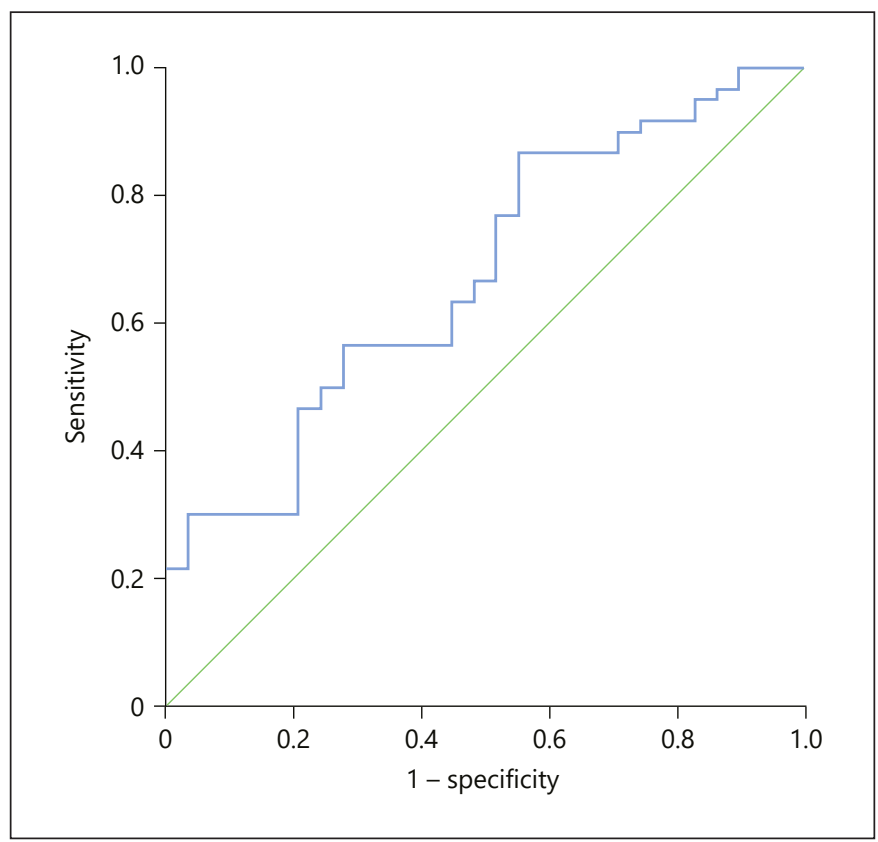

Fig. 2. ROC analysis depicting sensitivity and specificity of serum GDF-15 level in the prediction of non-dipping BP pattern.

$0.038)$, septal $\mathrm{E} / \mathrm{E}^{\prime}$ ratio $(r=0.344, p=0.001)$, lateral $\mathrm{E} / \mathrm{E}^{\prime}$ ratio $(r=0.366, p<0.001)$, nighttime systolic BP $(r=$ $0.166, p=0.046)$, and nighttime diastolic BP $(r=0.188$, $p=0.024)$; however, a negative correlation of GDF-15 was evident with septal and lateral $\mathrm{E}^{\prime}$ velocities $(r=0.268, p=$ 0.005 and $r=0.236, p=0.013$; respectively) (Table 2 ).

In multivariate logistic regression analysis, serum GDF-15 level (OR: 1.018; 95\% CI: 1.01-1.029, $p=0.029$ ) and nighttime diastolic BP (OR: 2.042; 95\% CI: 1.487$2.804, p<0.001$ ) remained independently associated with the non-dipping BP pattern after adjustment for the traditional confounding factors (Table 3 ). In the ROC anal$y$ sis, the optimal cutoff value for GDF-15 to predict a nondipping BP pattern with $56.7 \%$ sensitivity and $72.4 \%$ specificity was $524.6 \mathrm{ng} / \mathrm{L}$ (AUC: $0.676,95 \%$ CI: 0.580 0.772, $p<0.05$ ) (Fig. 2).

\section{Discussion}

The main findings of our study can be summarized as follows: (1) serum GDF-15 levels were greater in nondippers, compared with the dippers and the healthy controls; (2) serum GDF-15 perpetuated its independent association with the non-dipping BP pattern, as evident in the multivariate logistic regression analysis; (3) serum
GDF-15 level was positively correlated with septal and lateral $\mathrm{E} / \mathrm{E}^{\prime}$ ratios, while negatively correlated with lateral and septal E' velocities; and (4) the appearance of a cutoff value in the ROC analysis of GDF-15 may suggest that this blood parameter is likely to be utilized as a diagnostic tool in non-dipper HT. In this regard, our study further expands the current literature on GDF-15 and HT. To our knowledge, it is the first research study where the relationship between serum GDF-15 level and non-dipping circadian pattern was evaluated, especially in HT patients without overt LVH.

GDF-15 is suggested to act as a regulatory cytokine that assumes a cardioprotective role through activation of various cellular receptors and is implicated in inflammatory and apoptotic pathways, as well as modulation of the sympathetic system [17-19].

Recently, GDF-15 appealed more and more to pertinent researchers as a promising diagnostic and prognostic marker for cardiometabolic diseases [20]. Previous studies reported an association of GDF-15 with poor CV outcomes in a variety of clinical settings such as acute coronary syndrome, stable coronary artery diseases, and heart failure $[18,20]$. In other studies, GDF-15 expression was reported to be upregulated under various stress conditions including pressure overload and sympathetic system activation $[19,21,22]$. Currently, studies evaluating the relationship between GDF-15 level and HT are scanty. In their study, Hanatani et al. [23] reported a significantly elevated serum GDF-15 level in patients with hypertensive $\mathrm{LVH}$, compared with healthy controls and patients with hypertrophic cardiomyopathy. Similarly, Kou et al. [11], in their recent study, demonstrated an elevated serum GDF-15 level in HT patients with LVH compared with those without LVH and controls. However, the GDF-15 level in their study was lower in HT patients without LVH compared with healthy controls. In another study by Xue et al. [12], the GDF-15 level in HT patients with LVH was found to be significantly greater compared with that of HT patients without LVH. However, there was no control group in their study. Since LVH in these studies was demonstrated to have an independent and significant association with GDF-15 level in general, we specifically intended in our study to exclude HT patients with LVH in order to obviate the likely effect of LVH on serum GDF-15 levels.

The fact that the non-dipping BP pattern is associated with more extensive end-organ damage and more prevalent CV end points due to a relatively higher degree of inflammation, endothelial dysfunction and pressure overload is well recognized [2, 24,25]. The non-dipping pattern is also associated with more impaired diastolic 
functions [26]. In this regard, Dinh et al. [21] suggested GDF-15 as a novel biomarker of deteriorating LV diastolic functions, regardless of the presence of well-established risk factors related with LV diastolic dysfunction such as coronary arterial disease and HT.

As for the autonomic nervous system status, the nondippers were reported to possess lower parasympathetic but higher sympathetic activities compared with the dippers [27]. In accordance with this, Xu et al. [19] reported on the basis of the in vivo and in vitro assays that norepinephrine was able to stimulate GDF-15 synthesis, and upregulated GDF-15 levels in turn exerted a negative feedback on the development of norepinephrine-induced myocardial hypertrophy. Even further, they reported a positive correlation of GDF-15 with ventricular remodeling even at the prehypertrophy stage of HT, suggesting a protective function of GDF-15 against chronic sympathetic activation. However, we consider that whether GDF-15 upregulation is a true cause or a true result of a non-dipping pattern is quite intricate and needs to be elucidated with future studies.

Considering the concomitance of a greater increase in sympathetic activity, worse diastolic functions, prolonged pressure overload, and more adverse $\mathrm{CV}$ outcomes in the non-dipping BP pattern, it is rational to assume that GDF-15 levels are greater in non-dippers compared with dippers, even in the absence of LVH.

This study should be evaluated together with some limitations. Our study is a single-center study and comprises a relatively small population. Moreover, we did not try to correlate GDF-15 levels with some other relatively novel anti-inflammatory and endothelium-protective biomarkers. The relatively small sample size of the study may have attenuated the statistical power, especially in the ROC analysis. We also did not follow up the participating patients for future CV events.

\section{Conclusion}

Our study showed elevated serum GDF-15 levels in non-dipper HT patients compared with both dippers and healthy controls. Additionally, GDF-15 level and nighttime diastolic BP were revealed to be independently associated with a non-dipping BP pattern. Our findings suggest that GDF-15 may serve as a predictor of a nondipping circadian pattern in patients with a new EH. However, future multicenter studies with larger populations are needed to confirm our findings.

\section{Statement of Ethics}

A written informed consent was obtained from every subject. This study complies with the Declaration of Helsinki, and the local ethics committee approved our study protocol.

\section{Disclosure Statement}

The authors have no conflict of interest to declare.

\section{References}

1 Kanbay M, Turkmen K, Ecder T, Covic A. Ambulatory blood pressure monitoring: from old concepts to novel insights. Int Urol Nephrol. 2012 Feb;44(1):173-82.

2 de la Sierra A, Redon J, Banegas JR, Segura J, Parati G, Gorostidi M, et al.; Spanish Society of Hypertension Ambulatory Blood Pressure Monitoring Registry Investigators. Prevalence and factors associated with circadian blood pressure patterns in hypertensive patients. Hypertension. 2009 Mar;53(3):466-72.

3 Bootcov MR, Bauskin AR, Valenzuela SM, Moore AG, Bansal M, He XY, et al. MIC-1, a novel macrophage inhibitory cytokine, is a divergent member of the TGF-beta superfamily. Proc Natl Acad Sci USA. 1997 Oct;94(21): 11514-9.

4 Wollert KC, Kempf T, Wallentin L. Growth Differentiation Factor 15 as a Biomarker in Cardiovascular Disease. Clin Chem. 2017 Jan; 63(1):140-51.
5 Wallentin L, Hijazi Z, Andersson U, Alexander JH, De Caterina R, Hanna M, et al.; ARISTOTLE Investigators. Growth differentiation factor 15, a marker of oxidative stress and inflammation, for risk assessment in patients with atrial fibrillation: insights from the Apixaban for Reduction in Stroke and Other Thromboembolic Events in Atrial Fibrillation (ARISTOTLE) trial. Circulation. 2014 Nov; 130(21):1847-58.

6 Cotter G, Voors AA, Prescott MF, Felker GM, Filippatos G, Greenberg BH, et al. Growth differentiation factor 15 (GDF-15) in patients admitted for acute heart failure: results from the RELAX-AHF study. Eur J Heart Fail. 2015 Nov; 17(11):1133-43.

7 Wang X, Chen LL, Zhang Q. Increased Serum Level of Growth Differentiation Factor 15 (GDF-15) is Associated with Coronary Artery Disease. Cardiovasc Ther. 2016 Jun;34(3): 138-43.
8 Mutlu LC, Altintas N, Aydin M, Tulubas F, Oran M, Kucukyalin V, et al. Growth Differentiation Factor-15 Is a Novel Biomarker Predicting Acute Exacerbation of Chronic Obstructive Pulmonary Disease. Inflammation. 2015 Oct;38(5):1805-13

9 Zhang S, Dai D, Wang X, Zhu H, Jin H, Zhao $\mathrm{R}$, et al. Growth differentiation factor- 15 predicts the prognoses of patients with acute coronary syndrome: a meta-analysis. BMC Cardiovasc Disord. 2016 May;16(1):82.

10 Wiklund FE, Bennet AM, Magnusson PK, Eriksson UK, Lindmark F, Wu L, et al. Macrophage inhibitory cytokine-1 (MIC-1/GDF15): a new marker of all-cause mortality. Aging Cell. 2010 Dec;9(6):1057-64.

11 Kou H, Jin X, Gao D, Ma R, Dong X, Wei J, et al. Association between growth differentiation factor 15 and left ventricular hypertrophy in hypertensive patients and healthy adults. Clin Exp Hypertens. 2018;40(1):8-15.
GDF-15 and Circadian Pattern of Hypertension
Med Princ Pract 2019;28:566-572 DOI: $10.1159 / 000501096$ 
12 Xue H, Fu Z, Chen Y, Xing Y, Liu J, Zhu H, et al. The association of growth differentiation factor-15 with left ventricular hypertrophy in hypertensive patients. PLoS One. 2012;7(10): e46534.

13 Mancia G, Fagard R, Narkiewicz K, Redon J, Zanchetti A, Böhm M, et al. 2013 ESH/ESC guidelines for the management of arterial hypertension: the Task Force for the Management of Arterial Hypertension of the European Society of Hypertension (ESH) and of the European Society of Cardiology (ESC). Eur Heart J. 2013 Jul;34(28):2159-219.

14 Quiñones MA, Otto CM, Stoddard M, Waggoner A, Zoghbi WA; Doppler Quantification Task Force of the Nomenclature and Standards Committee of the American Society of Echocardiography. Recommendations for quantification of Doppler echocardiography: a report from the Doppler Quantification Task Force of the Nomenclature and Standards Committee of the American Society of Echocardiography. J Am Soc Echocardiogr. 2002 Feb;15(2):167-84.

15 Devereux RB, Alonso DR, Lutas EM, Gottlieb GJ, Campo E, Sachs I, et al. Echocardiographic assessment of left ventricular hypertrophy: comparison to necropsy findings. Am J Cardiol. 1986 Feb;57(6):450-8.
16 Lang RM, Badano LP, Mor-Avi V, Afilalo J, Armstrong A, Ernande L, et al. Recommendations for cardiac chamber quantification by echocardiography in adults: an update from the American Society of Echocardiography and the European Association of Cardiovascular Imaging. Eur Heart J Cardiovasc Imaging. 2015 Mar; 16(3):233-70.

17 Ago T, Sadoshima J. GDF15, a cardioprotective TGF-beta superfamily protein. Circ Res. 2006 Feb;98(3):294-7.

18 Schopfer DW, Ku IA, Regan M, Whooley MA. Growth differentiation factor 15 and cardiovascular events in patients with stable ischemic heart disease (The Heart and Soul Study). Am Heart J. 2014;167:186-192.e1.

19 Xu XY, Nie Y, Wang FF, Bai Y, Lv ZZ, Zhang YY, et al. Growth differentiation factor (GDF)-15 blocks norepinephrine-induced myocardial hypertrophy via a novel pathway involving inhibition of epidermal growth factor receptor transactivation. J Biol Chem. 2014 Apr;289(14):10084-94.

20 Adela R, Banerjee SK. GDF-15 as a Target and Biomarker for Diabetes and Cardiovascular Diseases: A Translational Prospective. J Diabetes Res. 2015;2015:490842.

21 Dinh W, Füth R, Lankisch M, Hess G, Zdunek D, Scheffold T, et al. Growth-differentiation factor-15: a novel biomarker in patients with diastolic dysfunction? Arq Bras Cardiol. 2011 Jul;97(1):65-75.
$22 \mathrm{Xu}$ J, Kimball TR, Lorenz JN, Brown DA, Bauskin AR, Klevitsky R, et al. GDF15/MIC-1 functions as a protective and antihypertrophic factor released from the myocardium in association with SMAD protein activation. Circ Res. 2006 Feb;98(3):342-50.

23 Hanatani S, Izumiya Y, Takashio S, Kojima S, Yamamuro M, Araki S, et al. Growth differentiation factor 15 can distinguish between hypertrophic cardiomyopathy and hypertensive hearts. Heart Vessels. 2014 Mar;29(2):231-7.

24 Izzedine H, Launay-Vacher V, Deray G. Abnormal blood pressure circadian rhythm: a target organ damage? Int J Cardiol. 2006 Mar; 107(3):343-9.

25 Larochelle P. Circadian variation in blood pressure: dipper or nondipper. J Clin Hypertens (Greenwich). 2002 Jul-Aug;4(4 Suppl 1):3-8.

26 Chen Y, Liu JH, Zhen Z, Zuo Y, Lin Q, Liu M, et al. Assessment of left ventricular function and peripheral vascular arterial stiffness in $\mathrm{pa}-$ tients with dipper and non-dipper hypertension. J Investig Med. 2018 Feb;66(2):319-24.

27 Okutucu S, Civelekler M, Aksoy H, Yetis Sayin B, Oto A. Assessment of pupillary autonomic functions by dynamic pupillometry in different circadian arterial blood pressure patterns. Blood Press Monit. 2018 Aug;23(4): 203-9. 